\title{
AVALIAÇÃO DE ESTRATÉGIAS PARA A REDUÇÃO DO RISCO DE INADIMPLÊNCIA EM CARTEIRAS DE CRÉDITO BANCÁRIO ROTATIVO DE PESSOAS FÍSICAS
}

\author{
ASSESSMENT OF DEFAULT RISK REDUCTION STRATEGIES IN \\ REVOLVING CREDIT PORTFOLIOS OF INDIVIDUAL BORROWERS
}

\author{
JOSÉ ODÁLIO DOS SANTOS \\ Pós-Doutorando no Departamento de Administração \\ da Faculdade de Economia, Administração e Contabilidade \\ da Universidade de São Paulo - SP \\ Professor Associado do Programa de Pós-Graduação em Administração \\ da Faculdade de Economia e Administração \\ da Pontifícia Universidade Católica de São Paulo - SP \\ E-mail: j.odalio@pucsp.br
}

\author{
RUBENS FAMÁ \\ Professor Doutor do Departamento de Administração \\ da Faculdade de Economia, Administração e Contabilidade \\ da Universidade de São Paulo - SP \\ Professor Titular do Programa de Pós-Graduação em \\ Ciências Contábeis e Atuárias \\ da Faculdade de Economia e Administração \\ da Pontifícia Universidade Católica de São Paulo - SP \\ E-mail:rfama@usp.br
}

\section{RESUMO}

Os principais Bancos Privados brasileiros vêm apresentando crescimento contínuo do número de clientes pessoas físicas em suas carteiras de crédito e, conseqüentemente, aumento do volume de negócios e receitas com as altas taxas de spread, ou retorno, cobradas em empréstimos rotativos (ex.: Limite de Cheque Especial). Como, paralelamente ao aumento da concessão de empréstimos, ocorre uma maior exposição ao risco de inadimplência, espera-se que os Bancos adotem ações preventivas e inibidoras ao não pagamento pontual de empréstimos. Visando contribuir nessa tarefa, este artigo, inicialmente, apresenta três proposições para a redução de risco em carteiras de crédito bancário rotativo às pessoas físicas, quer sejam: 1) "O Agente Desestimulador ao Risco Moral", 2) "A Determinação da Fronteira Eficiente Risco-Retorno" e 3) "O Mercado Futuro de Índices de Inadimplência". Na parte final, apresenta um modelo econométrico desenvolvido para avaliar o impacto de 19 variáveis sistemáticas na inadimplência de pessoas físicas em créditos rotativos. Os resultados extraídos de simulações conduzem à conclusão parcial de que a utilização do modelo econométrico e a implementação das três estratégias contribuiriam para a inibição e melhor monitoramento da inadimplência em carteiras de crédito rotativo de pessoas físicas.

Palavras-chave: Crédito Pessoal; Risco de Inadimplência; Carteira de Crédito.

\section{ABSTRACT}

In recent years, the main private Brazilian banks have presented a continuous increase in the number of clients in their portfolios and, consequently, successive growth of credit operations and revenues obtained through the high interest rates or spread charged on loans to individual borrowers, such as credit limit and revolving credit. Moreover, the increase in the number of clients also increases the risk of default. Hence, it is essential that banks carry out strategies to implant default prevention actions. In order to contribute to this endeavor, this paper presents three propositions or action strategies, aimed at reducing risks in natural-person revolving credit portfolios: 1. "The Moral Risk Discouraging Agent", 2. The Determination of the Efficient Risk-Return Frontier", and 3. "The Futures Market of Default Ratios". This paper also proposes an econometric model to assess the impact of nineteen systemic variables related to individual default risk observed in revolving credit. The results obtained through the simulations led to the conclusion that the econometric model and the implementation of each of the three strategies contribute to the inhibition and better monitoring of default in individual revolving credit portfolios.

Keywords: Consumer Credit, Default Risk, Credit Portfolio. 


\section{INTRODUÇÃO}

Para manter as elevadas taxas históricas de rentabilidade, a partir da implantação do Plano Real, em junho de 1994, os Bancos compensaram a perda da receita inflacionária com o aumento de ganhos sobre passivos não indexados, prestação de serviços beneficiada pela liberação da cobrança de tarifas, receitas de operações com títulos e valores mobiliários e expansão das concessões de crédito lastreadas pela elevação dos depósitos a vista e a prazo.

Para o vasto mercado de pessoas físicas, o aumento das concessões de crédito vem gerando uma elevada taxa de retorno ("spread") aos Bancos e, em contrapartida, uma maior exposição ao risco de inadimplência, ou seja, a do não recebimento (parcial ou total) das parcelas do crédito.

O Quadro 10 apresenta dados dos últimos 5 anos que evidenciam o favorável trade-off risco-retorno no segmento de pessoas físicas, medido pelos elevados spreads médios obtidos pelos Bancos.

Ao analisar-se o histórico de bons resultados financeiros dos principais Bancos Privados nacionais, principalmente gerados por ganhos nas concessões de empréstimos rotativos, considera-se como oportuna a ocasião para analisar a contribuição de três proposições para a redução de risco em carteiras de crédito bancário rotativo às pessoas físicas, quer sejam: 1) "O Agente Desestimulador ao Risco Moral", 2) "A Determinação da Fronteira Eficiente Risco-Retorno" e 3) "O Mercado Futuro de Índices de Inadimplência". Além disso, desenvolveu-se um modelo econométrico para identificação dos principais fatores sistemáticos sinalizadores da elevada probabilidade de inadimplência de pessoas físicas em créditos rotativos.

A pesquisa destaca-se pela originalidade e por abordar um assunto importante para as comunidades acadêmica e empresarial, uma vez que é atribuído ao crédito rotativo uma relevante alternativa de complemento de renda para que as pessoas físicas possam financiar suas necessidades de curto prazo.

\begin{tabular}{|l|r|r|r|r|r|}
\hline Itens/Período & $\mathbf{2 0 0 1}$ & $\mathbf{2 0 0 2}$ & $\mathbf{2 0 0 3}$ & $\mathbf{2 0 0 4}$ & $\mathbf{2 0 0 5}$ \\
\hline Volume de Crédito às Pessoas Físicas (em R\$ Bilhões) & 58,0 & 69,0 & 88,0 & 113,0 & 155,0 \\
\hline Taxa de Inadimplência Média (\%) & 5,4 & 5,7 & 5,9 & 6,2 & 6,8 \\
\hline Taxa Média Anual de Captação (\%) & 16,2 & 16,8 & 17,1 & 17,6 & 16,5 \\
\hline Spread Médio Anual (\%) & 41,4 & 41,7 & 42,3 & 42,9 & 42,8 \\
\hline
\end{tabular}

Fonte: Banco Central do Brasil, 02/2006.

Quadro 1 Dados Consolidados Médios do Mercado de Crédito de Pessoas Físicas

\section{FUNDAMENTAC̣ÃO TEÓRICA}

\subsection{Estratégia 1: “O Agente Desestimulador ao Risco Moral"}

Após a concessão do empréstimo, espera-se que os tomadores mantenham-se leais (pontuais na amortização do empréstimo), sempre que o valor de seus recursos financeiros (renda) seja superior ao valor das prestações do empréstimo. Contrariamente, atribui-se uma maior probabilidade de inadimplência quando o valor da renda for insuficiente para amortizar as prestações do empréstimo. Hui, Wong e Man (2006, p. 343) consideram que a probabilidade de inadimplência aumenta quando o valor dos ativos patrimoniais e financeiros dos tomadores é inferior ao valor de suas dívidas na data de amortização.

Para determinar a qualidade dos tomadores que se candidatam à obtenção de empréstimos, Stiglitz e Weiss (1981, p. 393-409) atribuíram às taxas de juros um importante sinalizador da inadimplência. Segundo argumento dos autores, todo concessor de financiamento assume uma tolerância de exposição ao risco de inadimplência, baseando-se no histórico de perdas em sua carteira de crédito. A tolerância máxima aos riscos de inadimplência baseia-se na concessão de empréstimos condicionada à cobrança de taxas de juros até o limite $\mathbf{i}$, o qual é estabelecido como parâmetro médio para concessão de empréstimo aos clientes de baixo e de alto risco. Acima de $\mathbf{i}$, os autores destacam dois comportamentos: (1) insatisfeitos com o aumento das taxas de juros, os tomadores de baixo risco - com acesso a outras fontes de financiamentos - desistem de novas solicitações de empréstimos e (2) desprovidos de fontes alternativas de financiamentos, somente tomadores de alto risco se candidatam à solicitação de novos empréstimos. Com a mudança da composição dos tomadores na carteira de empréstimos, os Bancos se expõem a maior probabilidade de inadimplência e, com isso, ficam sujeitos à obtenção de menores margens de lucratividade.

A Figura 10 mostra a relação entre o resultado esperado sobre o empréstimo e o preço das taxas de juros.

Diante da possibilidade da seleção adversa (concessão de empréstimos predominantemente para clientes de alto risco) - principalmente observada em cobranças de taxas de juros superiores a $\mathbf{i}$-, os Bancos ficam mais expostos ao risco de inadimplência, ou seja, o do não recebimento 


\section{Retorno esperado sobre o empréstimo}

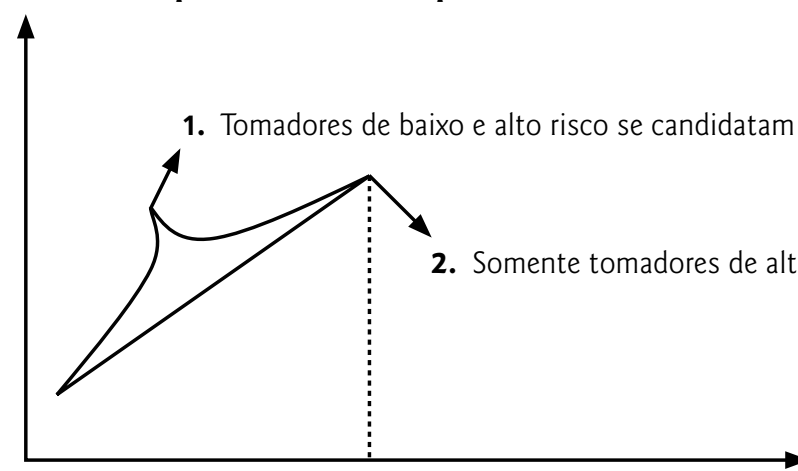

\section{Taxa de juros}

Fonte: Autores

Figura 1 \|| Composição Esperada de Tomadores na Carteira de Crédito com o Aumento da Taxa de Juros (i)

(total ou parcial) das parcelas do crédito nas datas fixadas no contrato de financiamento. McCoy, Frieder e Hedges (1994, p. 271-287) e Braga (1998, p. 48) justificam que a seleção adversa é decorrente das imperfeições na análise de crédito, quando os analistas tomam suas decisões baseando-se em informações imperfeitas, ou seja, incompatíveis com as reais condições de pagamento dos tomadores. Grablowsky (1973), Jaffe e Russel (1976) e Yezer, Phillips e Trost (1994) classificam esses tomadores como "desonestos" quando adotam ações oportunistas e percebem que o "Fator Utilidade em Inadimplir" oferece maiores benefícios que o "Fator Utilidade em Adimplir".

Visando amenizar tal exposição de risco, a proposição é a da adoção do efeito desestimulador à inadimplência, através da devolução de parte dos juros aos tomadores com histórico de pontualidade na amortização das dívidas contraídas ao longo do relacionamento.

Para explicar o "Fator Utilidade" dessa proposição, segue abordagem sobre os riscos assumidos pelos Bancos, antes e após a concessão do empréstimo. No primeiro período (1), o tomador obtém o crédito do Banco e, no segundo período (2), ele deverá amortizá-lo, baseando-se na existência de renda futura. Como a renda é determinada por fatores externos e, portanto, é dependente da situação econômica, o Banco acaba por assumir riscos no período inicial, em face das incertezas quanto à capacidade futura de pagamento do tomador. Cosci (1993, p. 22-49) destaca dois tipos de incertezas enfrentadas pelos bancos. O primeiro tipo de incerteza relaciona-se à incapacidade de os Bancos controlarem o comportamento de fatores externos (ex.: volatilidade das taxas de inflação, juros, câmbio). O segundo relaciona-se à intencionalidade dos devedores (caráter) para a amortização do empréstimo, em conformidade com as condições previstas nos contratos.

Seguem notações ajustadas por Santos (2000, p. 109112), baseadas no Modelo de Rea (1984, p. 188-208), para o entendimento dessa proposição:

- $\mathbf{C} \mathbf{i}=$ Projeto ou investimento analisado pelo tomador;

- $\mathbf{U}(\mathbf{C} 1)=$ Utilidade no período 1 ;
- $\mathbf{U}(\mathbf{C 2})=$ Utilidade no período 2;

- $\mathbf{E}=$ Valor do empréstimo ou principal;

- $\mathbf{r}=$ Taxa de juros cobrada sobre o empréstimo;

- $\mathbf{p}=$ Probabilidade de recebimento do empréstimo;

- $\mathbf{P}_{\mathbf{s}}=$ Valor da perda de renda alegada pelo tomador;

- $\mathbf{B}=$ Benefício ou bônus concedido ao tomador;

- $\mathbf{S}=$ Renda ou salário informado pelo tomador;

- $\mathbf{M}=$ Multa ou punição ao tomador pela ação desleal e

- $\mathbf{R}=$ Reputação ou Idoneidade no mercado de crédito.

Na fase de prospecção (período 1) e de monitoramento (período 2) do empréstimo, os Bancos assumem incertezas e riscos associados ao direcionamento dos recursos (E) que os tomadores realizarão para financiar os seus projetos $(\mathbf{C i})$. Por outro lado, os Bancos, também, se expõem à imprevisibilidade do caráter dos tomadores, os quais poderão adotar ações oportunistas quando perceberem maiores vantagens em inadimplir no período 2 [U(C2)], do que se manterem leais à amortização do empréstimo - conforme esperado no período 1 [U(C1)].

Ao decidir pela concessão do empréstimo, baseado na renda (S) e inexistência de informações desabonadoras no mercado, o Banco espera ganhar uma taxa de juros sobre o empréstimo (r), a qual representa a quantia a ser paga pelo tomador no período 2 mais o valor principal, ou seja, $\mathbf{E}(\mathbf{1}+\mathbf{r})$. Com os riscos inerentes aos negócios e caráter do tomador, decorre que o Banco estimará o retorno sobre o empréstimo, baseando-se em uma probabilidade de recebimento (p). Longhofer e Peters (1998, p. 6-7) abordam a necessidade de atribuição de uma probabilidade de recuperação para empréstimos, ao considerarem que os concessores de financiamentos não conseguem observar perfeitamente as ações dos tomadores. Para minimizar o risco da seleção adversa, os autores destacam a importância da determinação da probabilidade de êxito na recuperação do empréstimo, baseada na qualidade das informações cadastrais, financeiras, patrimoniais e de idoneidade do cliente.

Caso haja a confirmação de que os tomadores perderam capacidade de pagamento (total ou parcial), no perí- 
odo 2 (Ps), aumenta o risco de inadimplência e, com isso, os Bancos podem ser forçados a renegociar o saldo devedor do empréstimo para reduzir possíveis perdas financeiras.

Àqueles tomadores em condições de prever a perda de renda futura $(\mathbf{S})$, a maximização da utilidade em inadimplir seria baseada na obtenção do empréstimo e, posteriormente, na renegociação condicionada à redução da taxa de juros e/ou na obtenção de abatimentos sobre o saldo devedor (B).

Para alertar os tomadores quanto aos prejuízos que eles teriam no caso de alegação negligente de perda da renda (total ou parcial), os Bancos estabeleceriam uma multa (M) a ser paga no período 2, a qual funcionaria como um fator inibidor ou de perda de utilidade. Com a cobrança da multa, espera-se uma menor propensão dos tomadores à inadimplência (Quadro 2 O) do que se manterem pontuais na amortização do empréstimo. O argumento é o de mostrar aos tomadores que o fator utilidade em tornar a renda errônea não seria maior do que o fator utilidade em mantê-la correta, uma vez que os levariam à contabilização de resultados financeiros desfavoráveis - além da má reputação (R) no mercado de crédito. Contrariamente, quando da postura leal ou pontual na amortização das parcelas do empréstimo, os tomadores seriam beneficiados pelo recebimento de um bônus (B), representado pelo abatimento no valor da dívida ou na taxa de juros.

Moura (1995, p. 108) e Mateut (2005, p. 659) abordam o papel da multa em contratos de empréstimos, ao considerarem que existem situações práticas nas quais os retornos efetivos para os Bancos são nominalmente maiores do que os previstos, quando são aplicadas multas e outras taxas contratuais ao saldo devedor para inibir e compensar o período em atraso.

A devolução de parte do valor dos juros cobrado sobre o empréstimo (B) aos tomadores, por isso, constitui-se em alternativa desestimuladora à prática de ações desleais ou oportunistas. Com a inclusão desse benefício na relação do "Fator Utilidade em manter-se Leal" ( $2^{\text {a }}$ coluna do Quadro $3 \mathbf{O}$ ), espera-se que os tomadores sejam convencidos quanto aos maiores benefícios da boa reputação (R), com o argumento de obterem condições mais favoráveis na renovação ou solicitação de novos empréstimos.
O exemplo, a seguir, mostra a penalização financeira aplicada aos tomadores desleais, em termos de juros sobre o valor principal e multas por atraso, como forma de alertá-los quanto aos maiores benefícios da pontualidade na amortização de empréstimos.

Período I: Fase de Prospecção

- Valor do empréstimo $=R \$ 5.000,00$

- Taxa de juros $=10 \%$ ao mês

- Multa sobre o saldo devedor $=2 \%+0,15 \%$ por dia de atraso

- Dias de atraso $=30$

- Benefício sobre amortização pontual = devolução de $5 \%$ do valor das taxa de juros

Período 2: Fase de Monitoramento

- Saldo devedor do empréstimo $=R \$ 5.000,00$

Fator Utilidade por Conduta Leal

- $\left[R \$ 5.000^{*}(0,10)-(R \$ 500 * 0,05)\right]=\mathbf{R} \$ \mathbf{4 7 5}$

Fator Utilidade por Conduta Desleal

- $\{(R \$ 500 * 0,05)+(5.000 * 0,10)+(R \$ 5.000 * 0,02)+$ $\left.R \$ 5.000 *\left[(1,0015)^{30}-1\right]\right\}=\mathbf{8 5 4 , 9 6}$

Relação "Conduta Desleal” versus "Conduta Leal”

- Índice $=\mathrm{R} \$ 854,96 / \mathrm{R} \$ 475=\mathbf{1 , 8 0}$

Interpretação:

A cada $\mathrm{R} \$ 1,00$ que o tomador desembolsaria na conduta leal, a proporção seria a de desembolsar $R \$ 1,80$ ou $80 \%$ a mais, na conduta desleal.

Ao agregar a multa financeira às penalidades atribuídas ao tomador pela falta de idoneidade (ex.: registro em banco de dados de inadimplentes da Serasa ou Equifax), concluise quanto às condições ideais para a defesa dessa proposição, como alternativa inibidora ao risco de inadimplência.

\subsection{Estratégia 2: "A Determinação da Fronteira Eficiente Risco-Retorno"}

Devinney (1985), Petersen e Rajan (1994, p. 3-6), Allen, DeLong e Saunders (2004, p.739) e Saha e Thampy

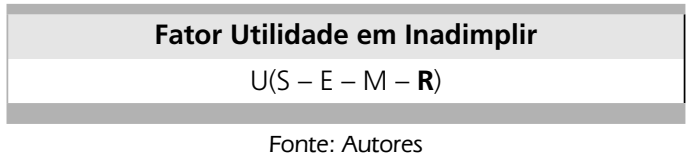

Quadro 2 | Fator Utilidade em Inadimplir

\begin{tabular}{|c|c|}
\hline Fator Utilidade em Inadimplir & Fator Utilidade em Manter-se Leal \\
\hline$U(S-E-M-\mathbf{R})$ & $\mathrm{U}(\mathrm{S}-\mathrm{E}+\mathbf{B}+\mathbf{R})$ \\
\hline
\end{tabular}

Fonte: Autores

Quadro 3 Fator Utilidade em Inadimplir e em manter-se Leal 
(2006, p.184) destacam o papel seletivo do relacionamento como importante recurso para obtenção de informações dos tomadores e adoção de ações preventivas para desestimular o risco moral, como a cobrança de multa financeira dos inadimplentes proposta neste artigo. Os autores sugerem que à medida que o relacionamento vai se estendendo, os credores passam a dispor de uma quantidade maior de informações dos tomadores e, assim, suas tomadas de decisões se ajustam mais adequadamente ao risco de crédito e seleção de garantias.

A liquidez dos Bancos está relacionada diretamente com a capacidade de conversão de empréstimos em caixa, em valores suficientes para honrar a demanda de saques dos poupadores. Todavia, a administração dessas variáveis está sujeita a limitações, ante as incertezas quanto ao caráter do tomador e a ocorrência de fatores sistemáticos prejudiciais à amortização de empréstimos. Gitman e Madura (2003, p.141) definem fatores sistemáticos como ocorrências externas, ou de mercado, que afetam o fluxo de caixa de empresas e pessoas físicas, tais como os aumentos das taxas de inflação, juros, tributos e câmbio.

Para reduzir o risco de inadimplência dos tomadores, primeiramente, pressupõe-se que a concessão de empréstimos esteja baseada na análise de informações evidenciadoras de capacidade de pagamento (internas e externas). Em seguida, considera-se fundamental a tarefa do monitoramento do empréstimo, através criação de sinalizadores de risco, como os índices de utilização máxima do limite de cheque especial (fronteira eficiente). Trata-se de mecanismo baseado na identificação da melhor relação entre o risco e o retorno para o Banco (SHARPE, ALEXANDER e BAILEY, 1999, p. 172).

$\mathrm{Na}$ Figura $2 \mathbf{0}$, visualiza-se a determinação do resultado ótimo para o Banco no ponto $\mathbf{r}$ ', em que o aumento do risco é compensado pelo aumento no retorno sobre o empréstimo. A partir desse referencial, os Bancos estariam mais expostos aos riscos de inadimplência, uma vez que somente tomadores de alto risco se candidatariam à solicitação de empréstimos. Conseqüentemente, a probabilida- de de recuperação do empréstimo diminuiria, não compensando o retorno auferido.

Para a determinação do ponto r', é indispensável que o Banco possua informações sobre o histórico da carteira em termos de receitas sobre empréstimos, despesas com a captação de fundos e perdas financeiras com a inadimplência dos tomadores. Com base nesses dados, atribui-se a probabilidade média de inadimplência (I), a taxa de juros média cobrada no empréstimo (TJ), o custo médio de captação dos fundos (CC) e o valor médio de concessão de empréstimo (V). A relação entre essas variáveis possibilita o cálculo do retorno esperado pelo Banco $\left(\mathbf{R}_{\mathrm{ESPS}}\right)$, conforme mostra a fórmula:

$$
R_{E S P \$}=\{[(1-I) *(T J-C C) * V]-(I * V)\}
$$

Sendo: $(\mathbf{1}-\mathbf{I})=$ Probabilidade de recebimento do empréstimo e $(\mathbf{T} \mathbf{J}-\mathbf{C C})^{*} \mathbf{V}=$ Spread ou retorno esperado sobre o valor do empréstimo

Como se trabalha sobre a hipótese de que os tomadores de alto risco tendem a estar muito endividados no limite de cheque especial, adaptou-se a fórmula ao agregar o sinalizador de risco baseado no índice de utilização do limite de cheque especial $\left(\mathrm{i}_{\mathrm{ce}}\right)$ :

$$
R_{E S P \$}=\left\{\left[(I-I) *(T J-C C)^{*} i_{c e} V\right]-\left(I^{*} i_{c e} V\right)\right\}
$$

A partir do cálculo do resultado esperado (em valor), determina-se o retorno percentual efetivo sobre o empréstimo $\left(\mathbf{R}_{\mathrm{EEET} \%}\right)$, através da relação entre o retorno esperado $e$ o valor da utilização do limite de cheque especial.

$R_{\text {EFET\% }}=\frac{\text { Retorno Esperado }}{(\text { Valor Utilizado no Limite de Cheque Especial) }}$

Segue simulação para o cálculo do retorno esperado sobre uma carteira de empréstimos de pessoas físicas, considerando as seguintes informações:

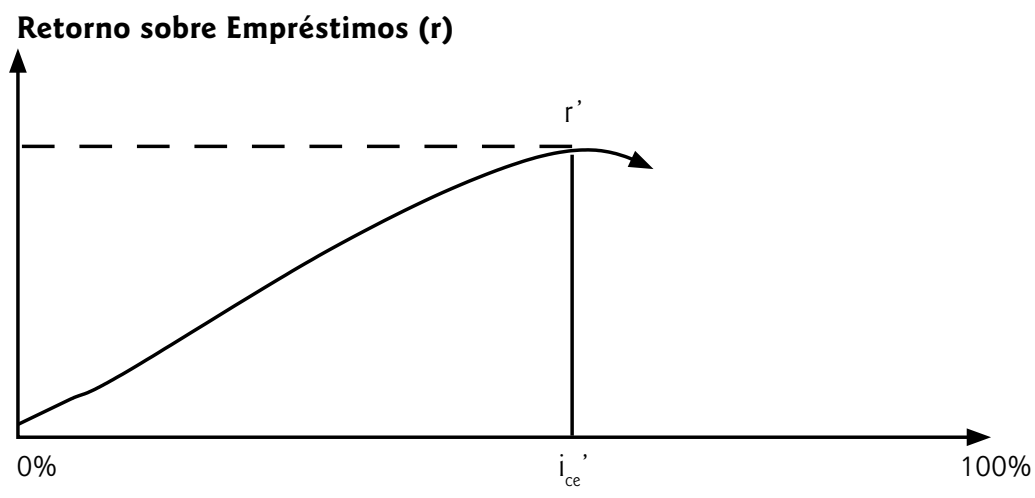

Índice de Utilização do Cheque Especial ( $\mathrm{i}_{\mathrm{ce}}$ )

Fonte: Autores

Figura 2 || Relação Índice de Utilização do Limite de Cheque Especial - Retorno 
- Valor do limite de cheque especial aprovado $=\$ 800$;

- Índice máximo de utilização do limite de cheque especial $=70 \%$;

- Probabilidade de recuperação até o valor máximo de utilização do limite de cheque especial = 97\%;

- Probabilidade de recuperação para o índice de utilização de $80 \%=96 \%$;

- Probabilidade de recuperação para o índice de utilização de 90\%= 95\%;

- Probabilidade de recuperação para o índice de utilização de $100 \%=94 \%$.

A partir do valor de utilização do limite de cheque especial tolerável $(70 \%$ de $\$ 800=\$ 560)$, os tomadores seriam classificados como de alto risco e, por isso, estariam sujeitos às conseqüências de ações preventivas, como as decorrentes da renegociação e do racionamento de empréstimos.

Os Quadros seguintes $\mathbf{O}$ apresentam as informações descritas, além dos procedimentos necessários, por etapa, para o cálculo e análise do retorno esperado (em valor e em percentual).
Na simulação apresentada, o retorno efetivo sobre o empréstimo calculado sobre o índice tolerável de utilização do limite de cheque especial $(4,80 \%)$ compreende o retorno ótimo para o Banco. A partir desse referencial, observa-se uma redução seqüencial do retorno efetivo sobre o empréstimo, justificando a adoção da fronteira eficiente para fins de otimização das variáveis risco e retorno.

\subsection{Estratégia 3: "O Mercado Futuro de Índices de Inadimplência"}

Brown e Smith (1993, p. 94) sustentam a hipótese de que as perdas potenciais de crédito com a inadimplência ocorrerão sempre que as taxas de juros se moverem adversamente. Entende-se que esse comportamento das taxas de juros influenciaria na qualidade de crédito e, portanto, na redução do retorno efetivo dos credores.

Em qualquer negócio ou investimento, os agentes econômicos alocam recursos no presente com base em ganhos esperados para o futuro. Contudo, na vida real as expectativas são incertas, uma vez que existem riscos de preços ou de retorno diretamente dependentes da ocorrência de

\begin{tabular}{|c|c|c|c|c|c|}
\hline $\begin{array}{c}\text { Índice de Utilização } \\
\text { do Limite de } \\
\text { Cheque Especial } \\
\left(i_{\mathrm{ce}}\right)\end{array}$ & $\begin{array}{l}\text { Probabilidade de } \\
\text { Recebimento do } \\
\text { Empréstimo } \\
(1-1)\end{array}$ & $\begin{array}{l}\text { Custo de Captação } \\
\text { para o Banco } \\
\text { (CC) }\end{array}$ & $\begin{array}{c}\text { Taxa de Juros } \\
\text { Cobrada no Limite } \\
\text { de Cheque Especial } \\
\text { (TJ) }\end{array}$ & $\begin{array}{l}\text { Valor Utilizado do } \\
\text { Limite de Cheque } \\
\text { Especial (\$800) } \\
\text { (V) }\end{array}$ & $\begin{array}{c}\text { Taxa de Retorno } \\
\text { Bancário } \\
\text { (Spread) }\end{array}$ \\
\hline $70 \%$ & $97 \%$ & $2 \%$ & $10 \%$ & $\$ 560$ & $8 \%$ \\
\hline $80 \%$ & $96 \%$ & $2 \%$ & $10 \%$ & $\$ 640$ & $8 \%$ \\
\hline $90 \%$ & $95 \%$ & $2 \%$ & $10 \%$ & $\$ 720$ & $8 \%$ \\
\hline $100 \%$ & $94 \%$ & $2 \%$ & $10 \%$ & $\$ 800$ & $8 \%$ \\
\hline
\end{tabular}

Fonte: Autores

Quadro 4 Resumo dos Dados

\begin{tabular}{|c|c|}
\hline $\begin{array}{c}\text { Retorno Esperado sobre o Índice de Utilização } \\
\text { do Limite de Cheque Especial }\left(\mathbf{R}_{\mathrm{ESPS}}\right)\end{array}$ & $\begin{array}{c}\text { Taxa de Retorno Esperado sobre o Índice } \\
\text { de Utilização do Limite de Cheque Especial }\end{array}$ \\
\hline $\mathbf{R}_{\mathrm{ESP}, 70 \%}=(0,97 * 0,08 * \$ 800 * 0,7)-(0,03 * \$ 560)=\mathbf{\$ 2 6 , 6 6}$ & $\$ 26,66 \div \$ 560=\mathbf{4 , 8 0 \%}$ \\
\hline $\mathbf{R}_{\mathrm{ESP}, 80 \%}=(0,96 * 0,08 * \$ 800 * 0,8)-(0,04 * \$ 640)=\mathbf{\$ 2 3 , 5 5}$ & $\$ 23,55 \div \$ 640=\mathbf{3 , 7 0 \%}$ \\
\hline $\mathbf{R}_{\mathrm{ESP}, 90 \%}=(0,95 * 0,08 * \$ 800 * 0,9)-(0,05 * \$ 720)=\mathbf{\$ 1 8 , 7 2}$ & $\$ 18,72 \div \$ 720=\mathbf{2 , 6 0 \%}$ \\
\hline $\mathbf{R}_{\mathrm{ESP}, 100 \%}=(0,94 * 0,08 * \$ 800 * 1,0)-(0,06 * \$ 800)=\mathbf{\$ 1 2 , 1 6}$ & $\$ 12,16 \div \$ 800=\mathbf{1 , 5 0 \%}$ \\
\hline
\end{tabular}

Fonte: Autores

Quadro 5 - Retorno sobre o Índice de Utilização do Limite de Cheque Especial

\begin{tabular}{|c|c|}
\hline Desempenho do Retorno Esperado Base: $\mathbf{R}_{\mathrm{ESP}, \mathbf{7 0}} \mathbf{=} \mathbf{\$ 2 6 , 6 6}$ & $\begin{array}{c}\text { Desempenho da Taxa de Retorno Esperada Base: } \mathbf{R}_{\mathrm{ESP}, \mathbf{7 0}}=\mathbf{4 , 8 0} \% \\
-\end{array}$ \\
\hline$[(\$ 23,55 \div \$ 26,66)-1]=\mathbf{- 1 1 , 7 0 \%}$ & {$[(3,70 \% \div 4,80 \%)-1]=\mathbf{- 2 2 , 9 0 \%}$} \\
\hline$[(\$ 18,72 \div \$ 26,66)-1]=\mathbf{- 2 9 , 8 0 \%}$ & {$[(2,60 \% \div 4,80 \%)-1]=-\mathbf{4 5 , 8 0 \%}$} \\
\hline$[(\$ 12,16 \div \$ 26,66)-1]=\mathbf{- 5 4 , 4 0 \%}$ & {$[(1,50 \% \div 4,80 \%)-1]=-\mathbf{6 8 , 8 0} \%$} \\
\hline
\end{tabular}

Fonte: Autores

Quadro 6 Desempenho do Retorno Esperado e da Taxa de Retorno Esperado 
fatores sistemáticos, como os relacionados com o aumento das taxas de juros, a recessão e o aumento do desemprego (GIESECKE e WEBER, 2006, p. 742). Esses fatores influenciam a perda da renda dos tomadores e, conseqüentemente, tendem a ser determinantes da inadimplência em empréstimos bancários.

Para explicar a relação entre a renda dos tomadores e a recuperação bancária do empréstimo (parcial ou total), consideram-se as seguintes notações visualizadas na Figura $3 \mathbf{0}$.

- $\mathrm{S}=$ Salário informado pelo tomador;

- $S^{\prime}=$ Salário de equilíbrio;

- $E=$ Valor total do empréstimo (principal + juros) e

- $\mathrm{G}=$ Garantia ou colateral vinculada ao empréstimo.

A análise da Figura 3 mostra que o resultado ótimo para o Banco ocorre quando a renda dos tomadores (S') é suficiente para a amortização do valor total do empréstimo $(\mathbf{E}=$ principal + juros $)$. À esquerda da renda de equilíbrio (S'), os Bancos expõem-se diante da possibilidade da não recuperação do valor total do empréstimo $(\mathbf{E})$, em virtude da perda de capacidade financeira dos tomadores. O ponto crítico ou de maior exposição ao risco de inadimplência ocorre quando os tomadores se encontram desempregados e, com isso, totalmente desprovidos de renda $(\mathbf{S}$ $\mathbf{= 0}$ ). Nesse caso, os Bancos apenas recuperarão parte do valor do empréstimo, caso consigam vender a garantia a valor de mercado $(\mathbf{G})$. O resultado negativo para o tomador decorrerá da perda patrimonial (-G) e da má reputação no mercado bancário, os quais são considerados importantes inibidores ao risco moral.

Em decorrência da relação negativa esperada entre a renda e o comportamento da inadimplência, a proposição é a da negociação no mercado futuro de um índice representativo das perdas bancárias em financiamentos às pessoas físicas. Trata-se de estratégia de proteção, baseada na cobertura das perdas financeiras em concessões de empréstimos através de ganhos resultantes de apostas no aumento ou na redução de um índice de inadimplência no mercado futuro. Similarmente, é o que Hull (1996, p.19) identifica como um contrato futuro, ou seja, um acordo para comprar ou vender um ativo por certo preço em determinada data futura.

Para a operacionalização dessa estratégia, a condição é a da existência de três agentes interagindo no mercado: (1) um Banco apostando no aumento ou na redução do índice futuro de inadimplência; (2) um intermediário financeiro e (3) investidores interessados em comprar e vender ativos representativos do índice futuro de inadimplência.

O cálculo do resultado financeiro com operações conjuntas de compra e venda no mercado futuro dar-se-ia mediante a determinação da pontuação (atual e futura) do índice de inadimplência de mercado, do número de contratos ótimos transacionados e do beta da carteira de empréstimo do Banco investidor (SANTOS, 2000, p. 115).

A determinação do número ótimo de contratos basearse-ia na fórmula:

\section{Valor da Carteira de Empréstimo}

(Número de Pontos*Valor de cada Ponto)

\section{* Beta Médio das Fontes de Renda dos Tomadores}

A inclusão de um coeficiente beta no cálculo do número ótimo de contratos baseia-se na condição de que os Bancos concedem empréstimos para tomadores, cuja renda assalariada é extraída de empresas atuando em diferentes atividades operacionais. Conseqüentemente, os Bancos, também, assumem riscos associados à situação financeira das fontes empresariais geradoras da renda dos tomadores, as quais seriam representadas pelos seus respectivos betas, ou seja, por medidas indicadoras do risco sistemático e interno de cada atividade operacional.

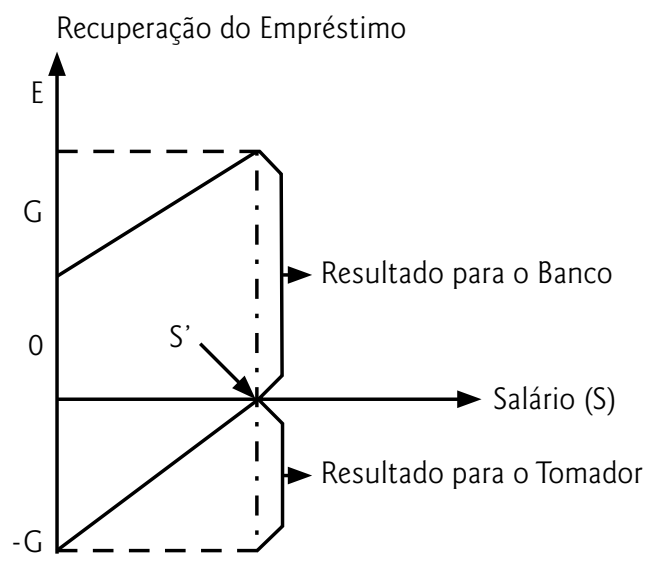

Fonte: Autores 


\begin{tabular}{|c|c|c|c|}
\hline Mercado à Vista & $\mathbf{t}_{\mathbf{o}}$ & $\mathbf{t}_{1}$ & Resultado: Inadimplência \\
\hline Valor da Carteira & $\mathrm{R} \$ 100.000 .000$ & $\mathrm{R} \$ 98.000 .000$ & $(\mathrm{R} \$ 2.000 .000)$ \\
\hline
\end{tabular}

Fonte: Autores

Quadro 7 Resultado Financeiro Proporcionado pela Carteira de Crédito no Mercado à Vista

\begin{tabular}{|c|c|c|c|}
\hline Mercado Futuro & $\mathbf{t}_{\mathbf{o}}$ & $\mathbf{t}_{\mathbf{1}}$ & Resultado: Lucro \\
\hline Valor da Carteira & $\begin{array}{c}12.000 \times 1.917 \times \mathrm{R} \$ 5,00 \\
=\mathrm{R} \$ 115.020 .000\end{array}$ & $\begin{array}{c}11.750 \times 1.917 \times \mathrm{R} \$ 5,00 \\
=\mathrm{R} \$ 112.623 .750\end{array}$ & $\mathbf{R} \mathbf{2 . 3 9 6 . 2 5 0}$ \\
\hline
\end{tabular}

Resultado Líquido $=$ R\$2.396.250 - R\$2.000.000 $=$ R\$396.250

Fonte: Autores

Quadro 8 Resultado Financeiro Proporcionado pela Carteira de Crédito no Mercado Futuro

A existência de uma carteira de empréstimos de mercado avaliada por pontos - similarmente à carteira de ações de mercado - constitui-se em condição ou referencial necessário para que os investidores possam avaliar a qualidade dos resultados financeiros com a realização das apostas.

Segue um exemplo:

Suponha as seguintes condições para um Banco administrando uma carteira de crédito composta por pessoas físicas:

Situação em $\mathbf{t}_{\mathrm{o}}$ :

- Valor da carteira $=\mathrm{R} \$ 100.000 .000$

- Tendência projetada pelo Banco para a inadimplência: alta

- Pontuação do Índice de inadimplência no mercado à vista $=12.000$ pontos

- Valor unitário do contrato $=R \$ 5,00$

- Beta da carteira representativo das fontes de renda dos tomadores $=1,15^{*}$

Um beta da carteira de crédito superior a 1 - representando o risco da atividade operacional das empresas geradoras da renda dos tomadores - seria considerado "agressivo", ou seja, estaria relacionado com a expectativa de geração de retorno superior ao proporcionado por uma carteira referencial de mercado. Em contrapartida, proporcionaria uma maior exposição aos riscos sistemáticos à carteira bancária, do que a proporcionada pela carteira referencial de mercado.

É importante destacar que a finalidade básica do exemplo é a de mostrar a técnica de como se beneficiar dessa estratégia de operação. Devido a esse fato, efetua-se uma simplificação operacional, visto que, nas operações, não estão incluídos os custos de corretagem e os ajustes diários ao final de cada pregão, conforme regras definidas pelas Bolsas de Valores para contratos futuros.

Estratégia:

Esse Banco, a fim de proteger a carteira de crédito contra os riscos sistemáticos, faz uma venda a futuro de um número determinado de contratos de índices de inadimplência.

Situação em $\mathbf{t}_{1}$ :

- Índice de inadimplência da carteira de mercado $=11.750$ pontos

Balanço financeiro da operação:

Número Ótimo de Contratos:

$\{[R \$ 100.000 .000 /(12.000 \times R \$ 5,00)] \times 1,15\}=\mathbf{1 . 9 1 7}$

\section{contratos}

Em caso de resultados líquidos positivos - como o exemplificado - é como se os Bancos estivessem vinculando uma proteção para a cobertura de perdas financeiras decorrentes da concessão de empréstimos para tomadores inadimplentes.

\section{MODELO ECONOMÉTRICO SINALIZADOR DA INADIMPLÊNCIA DE PESSOAS FÍSICAS EM CARTEIRAS DE CRÉDITO ROTATIVO}

\subsection{Introdução}

Após a aprovação de limites de crédito rotativo (Limite de Cheque Especial) às pessoas físicas, os Bancos expõemse às incertezas quanto ao risco moral e comportamento de fatores sistemáticos, os quais podem levá-los ao reconhecimento de perdas financeiras, quando a concessão de empréstimos for direcionada para tomadores inadimplentes. Para Hördahl, Tristani e Vestin (2006, p. 405-406), os riscos sistemáticos, ou fundamentos de mercado, devem ser incluídos em modelos econométricos para avaliar até que ponto contribuem para a determinação do prêmio pelo risco em títulos.

Visando analisar a relação entre sinalizadores de inadimplência e fatores sistemáticos, desenvolveu-se um modelo econométrico, com os seguintes objetivos:

10 Determinar o impacto agregado de 19 variáveis sistemáticas nos indicadores de inadimplência de pessoas físicas em créditos rotativos; 
2을 Identificar no modelo econométrico as variáveis sistemáticas que apresentaram a maior contribuição explicativa da inadimplência em créditos rotativos.

O período de análise vai de junho/1994 a junho/2004 e tem como principal influenciador a mudança do cenário econômico, caracterizada pela ocorrência de três fatores sistemáticos: (1) a redução significativa da inflação; (2) o aumento no volume de empréstimos às pessoas físicas e (3) o aumento da inadimplência em carteiras de empréstimos compostas por pessoas físicas.

Para obtenção e análise do modelo de regressão múltipla com o maior poder explicativo da inadimplência em carteiras de empréstimos rotativos às pessoas físicas, seguem-se os seguintes passos:

- Coleta de dados em entidades gerenciadoras de informações da atividade econômica e do mercado bancário;

- Análise intuitiva da relação dos dados com a inadimplência;

- Análise da matriz de correlação para selecionar variáveis explicativas altamente correlacionadas com a variável dependente;

- Análise residual para verificação de pontos com afastamentos significativos da média;

- Introdução dos dados no programa "Professional Statistics 11.0" - convertidos para padrão logarítmico (LG) -, para obtenção do modelo econométrico, através da metodologia "passo-a-passo". David e Patrick (1993) recomendam a utilização do processo "passo-a-passo", em que são incluídas, sucessivamente, no modelo as variáveis independentes (Xs) mais fortemente correlacionadas com a variável dependente $(\mathrm{Y})$, sendo feita, após cada inclusão, uma análise para se verificar se alguma variável anteriormente incluída deve ser descartada. Dessa forma, procura-se chegar a uma equação não sobrecarregada pela presença de variáveis que não contribuem significativamente para a explicação do fenômeno pesquisado.

O desenvolvimento do modelo econométrico voltado para a identificação dos principais fatores determinantes da inadimplência enfrentada pelos Bancos em concessões de empréstimos rotativos às pessoas físicas, baseou-se na análise do seguinte conjunto de informações estatísticas:

- o Teste $\mathbf{F}\left(\mathbf{F}_{\text {test }}\right)$ para a verificação da significância estatística do modelo econométrico como um todo. Através do $\mathrm{F}_{\text {test }}$ conclui-se que pelo menos uma das variáveis independentes explica uma proporção significativa da variação na varíavel dependente. Essa condição é parcial e, portanto, não se estende a todas as variáveis que compuseram o modelo de regressão;

- o Teste $\mathbf{t}\left(\mathbf{t}_{\text {test }}\right)$ para a verificação da significância estatística de cada variável independente incluída no modelo econométrico. Para a análise da significância de cada variável independente incluída nos modelos, adota-se os valores críticos 1,96 e 1,65, relacionados, respectivamente, aos intervalos de confiança de 5\% e 10\%;

- o Coeficiente de Determinação Ajustado $\left(\mathbf{R}^{2}\right)$ para a verificação percentual de quanto o modelo é explicado pelo conjunto de variáveis independentes;

- e o Coeficiente de Durbin-Watson (DW) para a verificação de existência de autocorrelação com padrão auto-regressivo de $1 \stackrel{a}{a}$ ordem na série temporal, ou seja, o grau de dependência da variável dependente em relação ao seu último valor histórico registrado.

\subsection{Variáveis Selecionadas}

Após o levantamento e análise dos dados consolidados da atividade econômica, em âmbito nacional, foram selecionadas 19 variáveis explicativas (independentes), agrupadas conforme os Quadros 9 a 120 .

Como sinalizador da inadimplência de pessoas físicas em empréstimos rotativos, selecionou-se a seguinte variável dependente conforme Quadro 130.

\subsection{O Modelo Econométrico}

Após a introdução das variáveis no Programa SPSS 11.0, distribuídas em valores mensais ajustados para o período de 10 anos, na metodologia passo-a-passo (stepwise process), chega-se ao seguinte modelo econométrico:

$$
\boldsymbol{L G}_{\text {CAL }}=\boldsymbol{F}\left[\left(L G_{A P L I C}, L G_{\text {FALENC }}, L G_{\text {DESEMP }}, L G_{\text {SPREAD }}, L G_{\text {COMB }}, L G_{\text {EMPHIP }}, L G_{\text {TXCHEQ }}\right)\right]
$$

\section{Fórmula:}

$\boldsymbol{L} \boldsymbol{G}_{C A L}=-36,71+2,12 L G_{A P L C}+0,29 L G_{\text {FALENC }}+1,18 L G_{\text {DESEMP }}-0,80 L G_{\text {SPREAD }}+0,61 L G_{\text {COMB }}+1,05 L G_{\text {EMPHIP }}+0,44 L G_{\text {TXCHEQ }}+\varepsilon$

Relação Verbal: O montante de créditos em atraso e em liquidação depende do valor de aplicações financeiras, do número de falências decretadas, da taxa de desemprego, da taxa de retorno em utilizações do limite de cheque especial, do consumo de combustíveis, do montante de empréstimos hipotecários e da taxa de juros cobrada em utilizações do limite de cheque especial. (Vide Quadro $14 \bullet$ ).

\subsection{Interpretação do Modelo Econométrico}

O Modelo LG $_{\mathrm{CAL}}$ apresentou um coeficiente de explicação ajustado de $98,40 \%$. Dentre as variáveis explicativas incluídas no modelo, as variáveis representativas do número de falências decretadas ( $\mathbf{L G}_{\text {FaLenc }}$ ), da taxa de desemprego $\left(\mathbf{L G}_{\text {DESEMP }}\right)$, do consumo de combustíveis ( $\mathbf{L G}_{\text {comB }}$ ), do valor 


\begin{tabular}{|l|l|c|}
\hline \multicolumn{3}{|c|}{ Indicadores de Venda de Bens (Duráveis e Não-Duráveis) } \\
\hline Indicador & Significado & Sigla \\
\hline Bens não-Duráveis & Venda de bens de consumo não-duráveis, convertidos à base 100 & $\mathrm{LG}_{\text {BENSND }}$ \\
\hline Televisores & Venda de televisores, em unidades & $\mathrm{LG}_{\text {TELEV }}$ \\
\hline Refrigeradores & Venda de refrigeradores, em unidades & $\mathrm{LG}_{\text {REFRGG }}$ \\
\hline Veículos de passeio & Venda de veículos de passeio, em unidades & $\mathrm{LG}_{\text {VEIC }}$ \\
\hline
\end{tabular}

Fontes: IBGE, Eletros e Anfavea

Quadro 9

\begin{tabular}{|l|l|c|}
\hline \multicolumn{2}{|c|}{ Indicadores de Consumo } \\
\hline Indicador & Significado & Sigla \\
\hline Energia Elétrica & Consumo residencial de energia elétrica, em GWH & $\mathrm{LG}_{\text {ENELET }}$ \\
\hline Combustíveis & Consumo de combustíveis, em mil m ${ }^{3}$ & $\mathrm{LG}_{\text {COMB }}$ \\
\hline Cimento & Consumo de cimento, em mil t & $\mathrm{LG}_{\text {CIMENT }}$ \\
\hline
\end{tabular}

Fontes: Eletrobrás, Petrobrás e SNIC

Quadro 10

\begin{tabular}{|c|c|c|}
\hline \multicolumn{3}{|c|}{ Indicadores da Atividade Econômica } \\
\hline Indicador & Significado & Sigla \\
\hline Desemprego & Índice percentual de desemprego & $\mathrm{LG}_{\text {DESEMP }}$ \\
\hline Inflação & Índice percentual de inflação & DUMMY $_{1 G P}$ \\
\hline Impostos & Impostos arrecadados (\$) pelo fisco sobre a renda de pessoas físicas & $\mathrm{LG}_{\mathrm{IRPF}}$ \\
\hline Excluídos do BC & Número de pessoas físicas excluídas da lista do Banco Central & $L G_{E B C}$ \\
\hline Falências & Número de falências decretadas & $\mathrm{LG}_{\text {FALENC }}$ \\
\hline
\end{tabular}

Fontes: IBGE, Fundação Getúlio Vargas, Secretaria da Receita Federal, Banco Central e SCI-Equifax

Quadro 11

\begin{tabular}{|l|l|c|}
\hline \multicolumn{2}{|c|}{ Indicadores da Atividade Bancária } \\
\hline Indicador & Significado & Sigla \\
\hline Empréstimos Individuais & Valor dos empréstimos às pessoas físicas (excluídos os hipotecários) & $L_{\text {EMPPFS }}$ \\
\hline Empréstimos Hipotecários & Valor dos empréstimos hipotecários & $L G_{\text {EMPHIP }}$ \\
\hline Cartões de Crédito & Valor das transações no comércio com a utilização de cartão de crédito & $L_{\text {CARTÃo }}$ \\
\hline Aplicações Financeiras & Valor de depósitos bancários à vista, em fundos a prazo e na poupança & $L_{\text {APLIC }}$ \\
\hline Reservas Bancárias & Valor das reservas financeiras bancárias & $L_{\text {RESBAN }}$ \\
\hline Taxa de Juros & Taxa de juros cobrada em utilizações do limite de cheque especial & $L_{\text {TXCHEQ }}$ \\
\hline Taxa de Retorno & Taxa de retorno (spread) sobre utilizações do limite de cheque especial & $L_{\text {SPREAD }}$ \\
\hline
\end{tabular}

Fontes: Banco Central e Associação Brasileira de Empresas de Cartões de Crédito

\section{Quadro 12}

\begin{tabular}{|l|l|l|}
\hline \multicolumn{2}{|c|}{ Variável Dependente (Y) } \\
\hline Indicador & Significado & Sigla \\
\hline Créditos em Atraso e em Liquidação & Valor de créditos em atraso e em liquidação & LG $_{\mathrm{CAL}}$ \\
\hline
\end{tabular}

Fontes: Banco Central

Quadro 13 


\begin{tabular}{|l|c|c|c|}
\hline Variáveis Independentes & Sinais Esperados & Coeficientes & $\mathbf{t}$ \\
\hline Constante & & $-36,71$ & $-9,09$ \\
\hline $\mathbf{L G}_{\text {APLIC }}$ & - & 2,12 & 9,60 \\
\hline $\mathbf{L G}_{\mathrm{FALENC}}$ & + & 0,29 & 3,44 \\
\hline $\mathbf{L G}_{\mathrm{DESEMP}}$ & + & 1,18 & 7,50 \\
\hline $\mathbf{L G}_{\text {SPREAD }}$ & + & $-0,80$ & $-4,63$ \\
\hline $\mathbf{L G}_{\text {COMB }}$ & + & 0,61 & 1,95 \\
\hline $\mathbf{L G}_{\text {EMPHIP }}$ & + & 1,05 & 2,28 \\
\hline $\mathbf{L G}_{\text {TXCHEQ }}$ & + & 0,44 & 2,03 \\
\hline $\mathbf{N}=120$ & $\mathbf{D W}=1,50$ & $\mathbf{F}=520,16$ & $\mathbf{R}_{\mathbf{a}}{ }^{2}=98,40 \%$ \\
\hline
\end{tabular}

Fonte: Autores

Quadro 14 Variável Dependente (Y): Créditos em Atraso e em Liquidação (LG $\left.\mathrm{CAL}_{\mathrm{AL}}\right)$

da concessão de empréstimos hipotecários ( $\left.\mathbf{L G}_{\text {EMPHIP }}\right)$ e da taxa de juros cobrada no cheque especial ( $\mathbf{L G}_{\text {TXCHEQ }}$ ) apresentaram coeficientes com sinais compatíveis com o esperado e perfeitamente admissíveis como influenciadoras do aumento da inadimplência em carteiras de empréstimos rotativos às pessoas físicas. Para explicar a participação dessas variáveis no modelo, adotou-se como possibilidade que o aumento das despesas orçamentárias (ex.: moradia e combustíveis), financiado através de endividamento no cheque especial, é desfavorável à capacidade de pagamento dos tomadores, uma vez que se trata de modalidade de financiamento condicionada ao pagamento de altas taxas de juros. A situação torna-se, ainda, mais desfavorável em épocas de recessão econômica, quando tende a ocorrer um aumento do número de falências empresarias e, conseqüentemente, da taxa de desemprego. Quanto aos sinais negativos dos coeficientes representativos do valor das aplicações financeiras $\left(\mathbf{L G}_{\text {Apuc }}\right)$ e da taxa de retorno bancário em utilizações do limite de cheque especial ( $\mathbf{L G}_{\text {SPREAD }}$ ), foram adotadas as seguintes possibilidades: (1) os tomadores, quando conhecedores da possibilidade da renegociação de empréstimos, poderiam adotar procedimentos desleais, como desviar os recursos financeiros para finalidades desconhecidas pelo Banco concessor (ex.: investimentos em negócios ou projetos de alto risco, amortização de empréstimos e/ou realização de ganhos financeiros em outros Bancos) e (2) em caso de insucesso nos investimentos realizados, esses tomadores ficariam desprovidos (total ou parcialmente) de recursos para cumprir a amortização do empréstimo e, com isso, forçariam o Banco a renegociar o saldo devedor condicionado à concessão de vantagens, o que inclui a redução da taxa de retorno.

\section{CONSIDERAÇÕES FINAIS}

O substancial aumento do lucro líquido dos Bancos, nos últimos anos, revela a crescente capitalização e viabilidade do setor: ver dados do Quadro $15 \mathbf{0}$.

Importante a destacar é que parte significativa desse resultado foi resultante de receitas em transações de crédito rotativo às pessoas físicas - principalmente nos produtos de cheque especial, em que as taxas de spreads ou retornos chegam a atingir patamares de até $10 \%$ ao mês.

Tratando-se de importante fonte geradora dos lucros bancários, este artigo apresentou três proposições ou estratégias de ação para o monitoramento de risco de inadimplência em carteiras de crédito rotativo às pessoas físicas, direcionadas àqueles Bancos interessados em man- ter ou aumentar suas já elevadas margens de rentabilidade. São elas: 1) "O Agente Desestimulador ao Risco Moral", 2) "A Determinação da Fronteira Eficiente Risco-Retorno" e 3) "O Mercado Futuro de Índices de Inadimplência". Para cada uma dessas proposições, os exemplos quantitativos simulados evidenciaram a viabilidade de implantação, como ação preventiva, nas práticas operacionais dos Bancos em suas tarefas de análise, concessão e monitoramento do risco de crédito. Complementarmente, apresentou-se um modelo econométrico com o objetivo de contribuir na identificação dos principais fatores sistemáticos que sinalizariam para o aumento da inadimplência em carteiras de créditos rotativos às pessoas físicas. As variáveis selecio-

\begin{tabular}{|l|c|c|c|}
\hline Indicadores Gerais & $\mathbf{2 0 0 0}$ & $\mathbf{2 0 0 5}$ & Var. (\%) \\
\hline Lucro Líquido (em R\$ Mil) & 7.821 .890 & 43.421 .455 & $455,13 \%$ \\
\hline
\end{tabular}

Fonte: Relatórios Bancários, 21/03/2005

Quadro 15 | Indicadores Gerais do Setor Bancário 2000 a 2005 — Inclui os Bancos Públicos 
nadas pelo Programa SPSS 11.0, mesmo que parcialmente questionáveis, apresentaram poder explicativo convincente $\left(\mathrm{R}_{\mathrm{a}}^{2}=98,40 \%\right)$ de eventos não controláveis (sistemáticos) que contribuiriam para o aumento da inadimplência em carteiras de crédito rotativo às pessoas físicas.

\section{Referências Bibliográficas}

ALLEN, L., DeLONG, G. e SAUNDERS, A.. Issues in the credit risk modeling of retail markets. Journal of Banking and Finance, $\mathrm{n}^{\circ} 28,2004$.

BRAGA, M. B.. A economia da informação e os mercados de crédito: algumas contribuições teóricas à moderna teoria da intermediação financeira. 1998. Tese de Doutorado defendida na USP, São Paulo.

BROWN, K. C.; SMITH, D. J.. Default risk and innovations in the design of interest rate swaps. Journal of the Financial Management Association, vol. 22, nº 2, Summer 1993 .

COSCI, S.. Credit rationing and asymmetric information. Dartmouth Publishing Company Limited, 1993.

DAVID, F.; PATRICK, W. S.. Business Statistics: a decision-making approach. Macmillan Publishing Co., p. 761-766, 1993.

DEVINNEY, T. M.. Rationing in a theory of the banking firm. Vanderbilt University, Working Paper, 1985.

GIESECKE, K.; WEBER, S.. Credit contagion and aggregate losses. Journal of Economic Dynamics \& Control, v. 30, no 5, May 2006.

GITMAN, L. J.; MADURA, J.. Administração financeira. São Paulo: Pearson Addison Wesley, 2003.

GRABLOWSKY, B. J.. A behavioral model of risk in consumer credit. Ph.D Thesis. 1973. The Ohio State University. Columbus: Ohio.

HÖRDAHL, P.; TRISTANI, O.; VESTIN, D.. A joint econometric model of macroeconomic and term-structure dynamics. Journal of Econometrics, v. 131, March/April, 2006.

HUI, C. H.; WONG, T. C.; MAN, P. K.. Measuring provisions for collateralised retail lending. Journal of Economics and Business, v. 58, Issue 4 , July-August, 2006.

HULL, J.. Introdução aos mercados futuros e de opções. São Paulo: Bolsa de Mercadorias e Futuros/Cultura Editores Associados, 1996.

JAFFE, D. M.; RUSSELL, T.. Imperfect information, uncertainty, and credit rationing. Quarterly Journal of Economics, no 90, November, 1976.

LONGHOFER, S. D.; PETERS, S. R.. Self-selection and discrimination in credit markets. Federal Reserve Bank of Cleveland. Working Paper, 9809, July 1998.

MATEUT, S.. Trade credit and monetary policy transmission. Journal of Economics Surveys, v. 19, nº 4, September, 2005.

McCOY, J. B.; FRIEDER, L. A.; HEDGES, R. B.. Bottom Line Banking: meeting the challenges for survival and success. Probus Publishing Company, 1994.

MOURA, H. J.. Metodologia multivariada para avaliação do risco de crédito de operações bancárias. 1995. Tese de Doutorado defendida na FGVSP. São Paulo.

PETERSEN, M. A.; RAJAN, R. G.. The benefits of lending relationships: evidence from small business data. The Journal of Finance, v.. 49, n 1 , March, 1994.

REA, S. A.. Arm-breaking, consumer credit and personal bankruptcy. Economic Inquiry, v. 22, nº 2, April 1984.

SAHA, B.; THAMPY, T.. Extractive bribe and default in subsidized credit programs. Journal of. Economics Behavior \& Organization, v. 60 , n०2,2006.

SANTOS, José O.. Uma contribuição ao estudo de fatores influenciadores da inadimplência de pessoas físicas em empréstimos bancários. 2000. Tese de Doutorado defendida na FGV-SP. São Paulo.

SHARPE, W. F.; ALEXANDER, G. J.; BAILEY, J. V.. Investments. 6 $6^{\text {th }}$ Editon. New Jersey: Prentice Hall, 1999.

STIGLITZ, J. E.; WEISS, A.. Credit rationing im markets with imperfect information. The American Economic Review, v. 71, nº 3, June, 1981.

YEZER, A. M. J.; PHILLIPS, R. F.; TROST, R. P.. Bias in estimates of discrimination and default in mortgage lending: the effects of simultaneity and self selection. Journal of Real Estate and Economics, v. 9, n 3, 1994.

\section{NOTA - Endereço dos autores}

Universidade de São Paulo

Faculdade de Economia, Administração e Contabilidade

Departamento de Administração

Av. Prof. Luciano Gualberto, 908 - Cidade Universitária

São Paulo - SP

05.508-900
Pontifícia Universidade Católica de São Paulo

Rua Ministro de Godói, 969 - Ed. Bandeira de Mello

- Perdizes

São Paulo - SP

05014-901 